|| Print ISSN: 2589-7837 || Online ISSN: 2581-3935 ||

International Journal of Medical Science and Diagnosis Research (IJMSDR)

Available Online at www.ijmsdr.com

NLM (National Library of Medicine ID: 101738824)

Original Research Article

Volume 6, Issue 1; January: 2022; Page No. 38-43

\title{
Dengue Fever: Clinical, Laboratory Profile and Outcome in Pediatric Patient
}

\section{Dr. Pooja Gandhi ${ }^{1}$, Dr Pinkal Taral ${ }^{2}$, Dr Krunal Patel ${ }^{3}$, Dr Sanketsinh Rathod $^{4}$, Dr Bhavini Rathwa ${ }^{5}$}

${ }^{1}$ Assistant Professor, Department of Pediatrics, Smt. Shardaben Hospital, Ahmedabad

${ }^{2}$ Final year Resident Doctor, Department of Pediatrics, Smt. Shardaben Hospital, Ahmedabad

${ }^{3} 2^{\text {nd }}$ year Resident Doctor, Department of Pediatrics, Smt. Shardaben Hospital, Ahmedabad

${ }^{4} 2^{\text {nd }}$ year Resident Doctor, Department of Pediatrics, Smt. Shardaben Hospital, Ahmedabad

${ }_{2^{2}}^{\text {nd }}$ year Resident Doctor, Department of Pediatrics, Smt. Shardaben Hospital, Ahmedabad

\section{Conflicts of Interest: Nil}

Corresponding author: Dr Pooja Gandhi

DOI: https://doi.org/10.32553/ijmsdr.v6i1.892

Abstract:

Introduction: Infection with any of the 4 dengue virus serotypes results in a diverse range of symptoms, from mild undifferentiated fever to life-threatening hemorrhagic fever and shock. Given that dengue virus infection elicits such a broad range of clinical symptoms, early and accurate laboratory diagnosis is essential for appropriate patient management. So a study was carried out to know its clinical profile, correlation between the laboratory profile and the severity of dengue fever and outcome in dengue patients.

Aim: To study the clinical profile, correlation between the laboratory profile and the severity of dengue fever and outcome in dengue patients at tertiary care center.

Method: Retrospective Observational study from 1st May 2019 to 31st April 2021.

Result: Total 323 patients were studied during 1st May 2019 to 31st April 2021. Most common presentation was fever $(100 \%)$, most common clinical finding is hepatomegaly $(14.2 \%)$. All severe dengue infection has platelet count $<50000$ /cumm. In study of 323 patients $194(60 \%)$ of dengue fever,85(26.4\%) of DHF GRADE 1,9(2.8\%) of DHF GRADE 2 were discharged .13(4\%) patients of DSS were expired.22 patients $(6.8 \%)$ went DAMA.

Conclusion: Reliable diagnosis of dengue fever in endemic areas can be done by clinical parameters like presence of nausea, vomiting, pain abdomen and hepatomegaly. Monitoring platelet count, hematocrit and WBC count is very useful for management of dengue cases.

Keywords: dengue fever, platelet count, outcome 


\section{Introduction:}

\section{Dengue virus}

The agent of dengue, i.e., dengue viruses, are categorized under the genus Flavivirus. These viruses contain single stranded RNA and are small in size $(50 \mathrm{~nm})$. There are four dengue virus serotypes which are designated as DENV-1, DENV-2, DENV-3 and DENV4. These serotypes may be in circulation either singly, or more than one can be in circulation in any area at the same time. Although all four serotypes are antigenically similar, they are different enough to elicit cross protection only for a few months after infection by any one of them. Infection with any one serotype confers lifelong immunity to the virus serotype. [1],[2]

Clinical findings of Dengue Fever are: acute onset, high grade and continuous fever, nausea and/ vomiting and abdominal pain. Haemorrhagic manifestations including a positive tourniquet test, petechiae, purpura, ecchymosis, epistaxis, gum bleeding, and haematemesis and/or melena. Hepatomegaly is also observed in children. Shock is manifested by tachycardia, poor tissue perfusion with weak pulse and narrowed pulse pressure (20 $\mathrm{mmHg}$ or less) and hypotension as cold, clammy skin and/or restlessness.

Lab features include: WBC count may be normal or with predominant neutrophils in the early febrile phase. Thereafter, there is a drop in the total number of white blood cells and neutrophils, reaching a nadir towards the end of the febrile phase. The change in total white cell count $(\leq 5000$ cells $/ \mathrm{mm} 3)$ and ratio of neutrophils to lymphocyte (neutrophils $<$ lymphocytes) is useful to predict theocratical period "of plasma leakage. This finding precedes thrombocytopenia or rising haematocrit. A relative lymphocytosis with increased atypical lymphocytes is observed by the end of the febrile phase and into convalescence. A sudden drop in platelet count to below 100000 occurs by the end of the febrile phase before the onset of shock or subsidence of fever. The level of platelet count is correlated with severity of DF. A sudden rise in haematocrit is observed simultaneously or shortly after the drop in platelet count. Haemoconcentration or rising haematocrit by $20 \%$ from the baseline is the objective evidence of plasma leakage. Thrombocytopenia, haemo-concentration and mildly elevated serum aspartate aminotransferase (AST/SGOT) levels $(\leq 200 \mathrm{U} / \mathrm{L})$ with the ratio of AST: ALT $(\mathrm{SGOT} / \mathrm{SGPT})>2$ are constant findings in DF. Partial thromboplastin time and prothrombin time are prolonged in about half and one third of DF cases respectively.[3]

Study Period: 1st May 2019 to 31st April 2021.

Study Site: Smt. Shardaben General hospital

Type Of Study: Retrospective Observational study Aims and Objective:

1. To study the clinical profile of paediatric patients with dengue fever.

2. To determine Correlation between the laboratory profile and the severity of dengue fever in Paediatric patients.

3. To study the outcome of dengue fever in paediatric patient.

\section{Materials and Methods:}

The present study was conducted in the pediatric department of the

tertiary care study institute.

1) Study Design: It was a prospective observational study

2) Study Area: It was conducted at Pediatric ward and Pediatric I.C.U. of a tertiary care center affiliated to medical college. In this hospital, there is a 64 bedded pediatric ward, including well equipped 3 bedded PICU and 2 
bedded Isolation room with adequate nursing staff and round-the clock pediatrician.

3) Study population: All patients of dengue attending the IPD of department of Pediatrics.

4) Duration of study- 02 years. (1-may-2019 to 31-april-2021)

5) Selection criteria: Following inclusion and exclusion criteria was used to select the study subjects.

\section{A) Inclusion criteria:}

All patients of dengue fever admitting in the department of Pediatrics.

A) Clinical Criteria: fever and two of the following

1)anorexia

2)rash

3)aches and pain

4)leukopenia

5)With warning sign: abdominal pain and tenderness, persistent vomiting, ascites, pleural effusion, mucosal bleeding, lethargy, restlessness, liver enlargement $>2 \mathrm{~cm}$, increase in hematocrit concurrent with rapid decrease in platelet count

B) laboratory criteria :(confirmatory criteria):

-dengue ns1 antigen detection (ELISA)

-IgM ELISA (by paired sera)

*Any one of the above

\section{B) Exclusion criteria:}

- A case with co-existing malaria or enteric fever will be excluded

Patient's clinical, demographic profile was noted, investigation and treatment as per protocol were observed. Results tabulated and appropriate statistical analysis done.

Mild dengue fever treatment includes paracetamol for fever and body ache and plenty of fluid.

Moderate dengue with warning sign treatment includes use of normal saline or Ringer's lactate. Severe dengue Fever treatment include use of colloids, inotrope, blood products like PRC, FFP, PCV, and fluid management.

Table 1: Clinical Features

\begin{tabular}{|l|l|l|}
\hline SYMPTOMS & YES & Peter P Vazhayil et al \\
\hline FEVER & $323(100)$ & $78(100)$ \\
\hline HEADACHE & $15(4.6)$ & $32(41)$ \\
\hline MYALGIA & $30(9.3)$ & $36(46.2)$ \\
\hline ARTHRALGIA & $6(1.8)$ & - \\
\hline RASH & $46(14.2)$ & $9(11.5)$ \\
\hline ABDOMINAL PAIN & $80(24.8)$ & $32(41)$ \\
\hline VOMITING & $114(35.3)$ & $50(64.1)$ \\
\hline COUGH & $195(60.4)$ & - \\
\hline COLD & $88(27.2)$ & - \\
\hline HEMORRHAGIC MANIOFESTATION & $17(5.3)$ & $9(11.5)$ \\
\hline CONVULSION & $20(6.2)$ & $2(2.6)$ \\
\hline FREQUENCY OF STOOL & $4(1.2)$ & - \\
\hline
\end{tabular}


Table 2: Clinical Findings on Admission

\begin{tabular}{|l|l|l|l|l|}
\hline Present Study & Rash & Mucosal Bleed & Hepatomegaly & Ascites \\
\hline DF & $18(62)$ & 0 & 0 & 0 \\
\hline DHF GRADE 1 & $6(20.6)$ & 0 & $37(80.4)$ & 0 \\
\hline DHF GRADE 2 & $2(6.9)$ & $4(36.4)$ & $4(8.6)$ & $1(25)$ \\
\hline DSS & $3(10.5)$ & $7(63.6)$ & $5(11)$ & $3(75)$ \\
\hline TOTAL (PRESENT STUDY) & $29(8.9)$ & $11(3.4)$ & $46(14.2)$ & $4(1.2)$ \\
\hline Peter P Vazhayil et al & $9(11.5)$ & $9(11.5)$ & $44(56.4)$ & $6(7.7)$ \\
\hline
\end{tabular}

Table 3: Blood Pressure on Admission According to Dengue Classification

\begin{tabular}{|l|l|l|l|l|}
\hline $\begin{array}{l}\text { BLOOD PRESSURE } \\
\text { ON ADMISSION }\end{array}$ & DF & $\begin{array}{l}\text { DHF } \\
\text { GRADE 1 }\end{array}$ & $\begin{array}{l}\text { DHF } \\
\text { GRADE 2 }\end{array}$ & DSS \\
\hline LOW & 0 & 0 & $2(16.7)$ & $13(100)$ \\
\hline NORMAL & $206(100)$ & $92(100)$ & $10(83.3)$ & 0 \\
\hline TOTAL & $206(100)$ & $92(100)$ & $12(100)$ & $13(100)$ \\
\hline
\end{tabular}

Table 4: Platelet Count at the Time of Admission

\begin{tabular}{|l|l|l|l|}
\hline Platelet Count & No of Cases & Total (Present Study) & Shwetha JH et al \\
\hline$<10000$ & $4(1.2)$ & $48(14.9)$ & $132(39.2)$ \\
\hline 10000 TO 50000 & $44(13.7)$ & & \\
\hline$>50000$ TO 100000 & $102(31.6)$ & $102(31.6)$ & $132(39.2)$ \\
\hline$>100000-150000$ & $53(16.4)$ & $173(53.5)$ & $72(21.6)$ \\
\hline$>150000$ & $120(37.1)$ & & \\
\hline
\end{tabular}

Table 5: WBC Count on Admission

\begin{tabular}{|l|l|l|}
\hline TOTAL LEUKOCYTE COUNT & NO. OF CASES & Shubhankar Mishra et al \\
\hline$<4000$ & $41(12.6)$ & $25(25.77)$ \\
\hline $4000-11000$ & $172(53.2)$ & $57(58.7)$ \\
\hline$>11000$ & $110(34.2)$ & $15(15.46)$ \\
\hline
\end{tabular}

Table 6: Distribution of Cases According to Haematocrit on Admission

\begin{tabular}{|l|l|l|l|l|l|l|}
\hline \multirow{2}{*}{$\begin{array}{l}\text { HEMATO- } \\
\text { CRIT (\%) }\end{array}$} & $\begin{array}{l}\text { Dengue Fever with and } \\
\text { without Warning Sign }\end{array}$ & \multicolumn{2}{l|}{ Severe Dengue } & \multicolumn{2}{l|}{ Senthil Kumar K et al } \\
\cline { 2 - 6 } & No of Cases & Total & No of Cases & Total & $\begin{array}{l}\text { Dengue Fever with and } \\
\text { without Warning Sign }\end{array}$ & $\begin{array}{l}\text { Severe } \\
\text { Dengue }\end{array}$ \\
\hline $20-30$ & $\begin{array}{l}55 \\
(17.7)\end{array}$ & $\begin{array}{l}194 \\
(62.6)\end{array}$ & 0 & 0 & $35(52.2)$ & $1(10)$ \\
\cline { 6 - 8 } & $\begin{array}{l}139 \\
(44.9)\end{array}$ & & 0 & & \\
\hline$>36.3-40$ & $\begin{array}{l}32 \\
(10.3)\end{array}$ & $\begin{array}{l}116 \\
(37.4)\end{array}$ & $\begin{array}{l}3 \\
(23)\end{array}$ & $\begin{array}{l}13 \\
(100)\end{array}$ & $32(47.8)$ & $9(90)$ \\
\hline$>40$ & $\begin{array}{l}84 \\
(27.1)\end{array}$ & & $\begin{array}{l}10 \\
(77)\end{array}$ & & & \\
\hline
\end{tabular}


Table 7: Outcome of Patients

\begin{tabular}{|l|l|l|l|}
\hline & DISCHARGE & DAMA & DEATH \\
\hline DENGUE FEVER & $194(60 \%)$ & $12(3.7 \%)$ & 0 \\
\hline DHF GRADE 1 & $85(26.4 \%)$ & $7(2.1 \%)$ & 0 \\
\hline DHF GRADE 2 & $9(2.8 \%)$ & $3(1 \%)$ & $\mathrm{O}$ \\
\hline DSS & $\mathrm{O}$ & $\mathrm{O}$ & $13(4 \%)$ \\
\hline TOTAL & $288(89.2 \%)$ & $22(6.8 \%)$ & $13(4 \%)$ \\
\hline
\end{tabular}

\section{Discussion:}

TOTAL 323 PATIENTS WERE STUDIED DURING 2 YEAR PERIOD.

In the present study the most common age group affected was more than 5 year of age 148 patients $(45.8 \%)$. This age group may be most commonly affected due to outward playing of older children.

In the present study most, common presentation was fever in all patients followed by cough in 195 patients $(60.4 \%)$ followed by vomiting in 114 patients $(35.3 \%)$. In study done by Peter P Vazhayil et al also had fever in all patients followed by vomiting in 50 patients $(64.1 \%)$.

In the present study hepatomegaly was the most common clinical finding in 46 patients (14.2\%) followed by rash in 29 patients $(8.9 \%)$ which was comparable to the study done by Peter P Vazhayil et al which also showed hepatomegaly in 44 patients $(56.4 \%)$.

In the present study capillary refill time was more than 3 seconds in all DSS patients on admission and equal to 3 second in 2 patients of DHF GRADE 2. In the present study low blood pressure for age was noted in all cases of DSS patients and 2 patients of DHF GRADE 2 also had low blood pressure. In the present study low blood pressure for age was noted in all cases of DSS patients and 2 patients of DHF GRADE 2 also had low blood pressure.

In the present study 120 patients $(37.4 \%)$ had platelet count $>1.5 \mathrm{lakh} /$ cumm and in the study done by Shwetha JH et al 132 patients (39.2\%) had platelet count in between $<10000 / \mathrm{cmm}$ to $50000 / \mathrm{cmm}$ and $>50000 / \mathrm{cmm}$ to $100000 / \mathrm{cmm}$.
This difference may be due to difference in sample size and varied presentation on admission. Platelet count less than $<50000 / \mathrm{cmm}$ was most commonly seen in severe dengue infection which suggest that platelet count has a predictive value in severity of infection So it indicates that according to severity of infection, platelet count decreases.

In the present study 172 patients $(53.2 \%)$ had normal WBC count which was comparable to Shubhankar Mishra et al study. $<4000 / \mathrm{cmm}$ WBC count was seen only 41 patients $(12.6 \%)$ only. Decreased WBC count is due to virus induced destruction or inhibition of myeloid progenitor cells.

In the present study hematocrit in $194(62.6 \%)$ patients had in the range of 20-36.3\% in dengue fever (with or without warning sign). In the study done by Senthil kumar $\mathrm{k}$ et al also had hematocrit in $52.2 \%$ patient in the range of 20 $36.3 \%$ in dengue fever (with or without warning sign). In both study all the patients of severe dengue had hematocrit of $>36.3 \%$ which suggests that hemoconcentration occurs in dengue infection as severity increases.

All patients of severe dengue infection required inotrope support since admission.

In the present study 13 patients required colloid support, 16 patients required $\mathrm{PRC}, 7$ patients required FFP, 8 patients required $\mathrm{PCV}$

\section{Conclusion}

Total 323 patient had study during 1st May 2019 to 31 st April 2021 period. Reliable diagnosis of dengue fever in endemic areas can be done by clinical parameters like presence of nausea, vomiting, pain abdomen and 
hepatomegaly. Monitoring platelet count, hematocrit and WBC count are very useful for management of dengue cases, especially for fluid administration and avoidance of unnecessary platelet transfusion.

All severe dengue infection has platelet count $<50000 / \mathrm{cmm}$. All severe dengue had hematocrit of $>36.5 \%$ which suggests that hemoconcentration occurs in dengue infection as severity increases. Low CRP was found in all the 3 groups of dengue fever, can be used to differentiate dengue fever from other diseases such as malaria, septic shock where CRP is elevated. In study of 323 patients $194(60 \%)$ of dengue fever,85(26.4\%) of DHF GRADE $1,9(2.8 \%)$ of DHF GRADE 2 were discharged $.13(4 \%)$ patients of DSS were expired.22 patients $(6.8 \%)$ went DAMA.

\section{Bibliography}

1. BaruahK, $\backslash$ BiswasA,SuneeshK,DhariwalA C.Denguefever:Epidemiologyandclinicalp athogenesis. Chapter 13, Major tropical diseases: Public health perspective. Goa: Broadway publishing House; 2014:25571.

2. Dutta AK, Biswas A, Baruah K, Dhariwal AC. National guidelines for diagnosis and management of dengue fever/dengue hemorrhagic fever and dengue shock syndrome. $\mathrm{J}$ Ind Med Assn. 2011;109(1):30-35.

3. Hand book for Clinical Management of Dengue, WHO July 2012: www.wpro.who. int $>$ mvp $>$ documents. (Accessed on 15th January 2017). 